\title{
VITAMIN-D DEFICIENCY AND RISK OF ACUTE CORONARY SYNDROME
}

\section{Original Article}

\author{
AYA HALLAK ${ }^{1}{ }^{*}$, MAHMOUD MALHIS ${ }^{2}$, MOHAMMAD YASER ABAJY1
}

${ }^{1}$ Department of Biochemistry and Microbiology, Faculty of Pharmacy, Aleppo University, Aleppo, Syria, ${ }^{2}$ Department of Cardiology, Aleppo University Hospital, Faculty of Medicine, Aleppo, Syria

Email: ph-aya@hotmail.com

Received: 05 Apr 2018 Revised and Accepted: 15 May 2018

\section{ABSTRACT}

Objective: This study aimed to investigate the relation between vitamin D plasma concentrations and prevalence of prespecified coronary risk factors, and to assess the role of vitamin D deficiency as an independent risk factor for the acute coronary syndrome (ACS).

Methods: In this study, plasma 25-hydroxyvitamin D [25(OH)D] levels were measured in 60 consecutive ACS patients at hospital presentation, and patient data including socio-demographics and clinical variables were recorded at the time of admission. We used the Independent samples T-test and the chi-square test to compare differences in the continuous and categorical variables, respectively. The partial correlation coefficient was used to measure association between plasma vitamin D levels and acute coronary syndrome while controlling for traditional cardiovascular risk factors.

Results: This study found significant associations between low plasma vitamin D levels and prevalence of hypertension and smoking. Whereas, no significant association between low plasma vitamin D levels and prevalence of diabetes mellitus (DM) was found. There was a statistically significant correlation between vitamin D deficiency and acute coronary syndrome, even after controlling for traditional cardiovascular risk factors $(P=0.028)$.

Conclusion: Vitamin D deficiency is independently associated with acute coronary syndromes, and could be an independent risk factor for the acute coronary syndrome (ACS).

Keywords: Vitamin D deficiency, Cardiovascular risk factors, Acute coronary syndrome

(C) 2018 The Authors. Published by Innovare Academic Sciences Pvt Ltd. This is an open access article under the CC BY license (http://creativecommons.org/licenses/by/4.0/) DOI: http://dx.doi.org/10.22159/ijpps.2018v10i6.26469

\section{INTRODUCTION}

Vitamin D is a major regulator of mineral ion homeostasis. Its deficiency is best known to cause rickets, osteomalacia and osteoporosis. Recent data, however, indicate broader roles for vitamin D in various biological processes through its active form, calcitriol or $1 \alpha, 25$-dihydroxyvitaminD [1 $\alpha, 25(\mathrm{OH}) 2 \mathrm{D}]$ [1]. Low levels of 25-hydroxyvitamin D [25(OH)D], the principal circulating storage form of vitamin $\mathrm{D}$, are present in as many as one third to one half of otherwise healthy middle-aged to elderly adults [2-5]. Limited cutaneous synthesis due to inadequate sun exposure or dark skin and inadequate dietary intake are the principal causes of low $25(\mathrm{OH}) \mathrm{D}$ levels.

Vitamin D, known primarily as a hormone of bone metabolism, can affect the transcription of a number of genes which play a pivotal role in both the development of acute coronary syndromes and the pathogenesis of coronary artery disease (CAD) [6]. In addition, vitamin D may inhibit the renin-angiotensin system [7], reduce parathyroid hormone levels [8], decrease coagulation [9], reduce inflammation $[10]$ thereby reducing atherosclerosis, and increase insulin production $[11,12]$. Epidemiologic studies have also recently linked vitamin D deficiency with increased risk of major adverse cardiovascular (CV) events [13]. A study of male health professionals showed a 2-fold risk of myocardial infarction (MI) in subjects who were vitamin D deficient compared with those in the sufficient range [14].

It has been recently reported that Vitamin D deficiency is common in patients with acute coronary syndromes (ACS) in Syria [15]. Early reports have linked Vitamin D deficiency to such cardiovascular (CV) conditions as hypertension, diabetes mellitus, obesity and the metabolic syndrome, left ventricular hypertrophy, heart failure, coronary heart disease, renal disease, and mortality [8, 14, 16-19]. However, a systematic review of 13 observational studies examining the association of vitamin D status with cardio-metabolic outcomes (type 2 diabetes, hypertension, or cardiovascular disease) concluded that the association is uncertain and the results were hampered by the heterogeneity of studies [20].

Because hypovitaminosis D is prevalent and readily treatable, establishing the relationship between vitamin D and risk of ACS is important. Thus, we examined plasma 25(OH)D concentrations relation to coronary risk factors, and assessed the role of vitamin D deficiency as an independent risk factor for the acute coronary syndrome (ACS).

\section{MATERIALS AND METHODS}

60 consecutive acute coronary syndrome patients admitted to the Cardiac Care Unit at affiliated hospitals of Aleppo University in Aleppo, Syria, were recruited. According to the European Society of Cardiology/American Heart Association redefined guidelines [21], patients were classified as ST-elevation myocardial infarction (STEMI; $\mathrm{n}=30$ ), non-ST elevation myocardial infarction (NSTEMI; $\mathrm{n}$ $=18$ ) and unstable angina (UA; $n=12$ ). A written informed consent was taken, and patient data including socio-demographics and clinical variables including hypertension, peripheral arterial disease, diabetes mellitus, previous AMI, previous angina, family history of coronary artery disease, and smoking history were recorded at time of admission. Hypertension was defined as systolic blood pressure $\geq$ $140 \mathrm{mmHg}$, diastolic blood pressare $90 \mathrm{mmHg}$, or use of antihypertensive therapy [22]. Criteria for diabetes mellitus were a fasting glucose $126 \mathrm{mg} / \mathrm{dl}$, use of insulin or hypoglycemic medications [23]. Active smoking was defined as current use of cigarette, hookah or pipe. Patients with renal diseases, hepatic diseases, or malignancy, those on phenytoin or other medications that can affect vitamin D and calcium metabolism like corticosteroid and bisphosphonates drugs, or who had recently received vitamin D or calcium supplements during the last three months, and patients who refused or unable to give consent were excluded from the study.

Blood samples for analysis were collected in liquid Lithium Heparin blood tubes on patient admission to the cardiac unit. Plasma was 
obtained immediately by centrifuging blood tubes $(3000 \mathrm{G}$ for 10 $\mathrm{min}$ ), and frozen at $-20{ }^{\circ} \mathrm{C}$ until further assessment. creatine kinase$\mathrm{MB}$ and troponin $\mathrm{T}$ levels were analyzed quantitatively by an electro chemi-luminescence technology using Cobas e411 module (Roche Diagnostics, Mannheim, Germany). Total vitamin D plasma level was measured by using a competitive solid phase enzyme-linked immunosorbent assay (competitive ELISA) (DiaMetra, Pozzulo, Italy). The lowest detectable concentration of 25(OH)D was 0.3 $\mathrm{ng} / \mathrm{ml}$, and no samples showed concentrations below the limit of detection.

Summary statistics are presented as frequencies and percentages for the categorical variables and as the mean values \pm standard deviation (SD) for the continuous variables. We used the Independent samples T-test and the chi-square test to compare differences in the continuous and categorical variables, respectively. The partial correlation coefficient was used to measure the association between plasma vitamin D levels and acute coronary syndrome while controlling for traditional cardiovascular risk factors. The prospectively defined risk factors of interest and available to study were age, gender, smoking, hypertension, diabetes mellitus, and previous cardiovascular diseases. The $25(\mathrm{OH}) \mathrm{D}$ cut point of 20 $\mathrm{ng} / \mathrm{ml}$ was used in this study [24], that compatible with at least moderate vitamin $\mathrm{D}$ deficiency. The referent group was prespecified as those having $25(\mathrm{OH}) \mathrm{D} \geq 20 \mathrm{ng} / \mathrm{ml}$. Although levels of $25(\mathrm{OH}) \mathrm{D}>$ $30 \mathrm{ng} / \mathrm{ml}$ are considered optimal for bone metabolism, only $5 \%$ of the study sample had levels in this range. All statistical analysis was performed using The Statistical Package for Social Sciences (SPSS version 20). A 2 -sided probability value $<0.05$ was considered statistically significant.

\section{RESULTS}

A total of 60 consecutive ACS patients (30 STEMI, 12 UA and 18 NSTEMI) were included in this study. Selected characteristics and biomarker levels of the participants are given in table 1 . The study subjects mean age was $55.30 \pm 10.40 \mathrm{y}$; men $(73.3 \%)$ outnumbered women $(26.7 \%)$.

Table 1: Selected characteristics and biomarker levels of the acute coronary syndrome patients

\begin{tabular}{ll}
\hline Variables & ACS patients $(\mathbf{N}=\mathbf{6 0})$ \\
\hline Age (years) & $55.30 \pm 10.40$ \\
Male/Female & $44(73.3 \%) / 16(26.7 \%)$ \\
Hypertension & $26(43.3 \%)$ \\
Smoking & $40(66.7 \%)$ \\
Diabetes Mellitus & $26(43.3 \%)$ \\
Previous Heart Disease & $26(43.3 \%)$ \\
Vit D $(\mathrm{ng} / \mathrm{ml})$ & $12.34 \pm 9.62$ \\
Troponin T $(\mathrm{ng} / \mathrm{ml})$ & $1.09 \pm 1.37$ \\
CK-MB $(\mathrm{ng} / \mathrm{ml})$ & $12.66 \pm 18.04$ \\
\hline
\end{tabular}

Among our patients, forty $(66.7 \%)$ patients were smokers and the mean of plasma $25(\mathrm{OH}) \mathrm{D}$ levels was $8.9 \pm 7.5 \mathrm{ng} / \mathrm{ml}$ in this group. The mean of plasma $25(\mathrm{OH}) \mathrm{D}$ levels was $19.1 \pm 9.8 \mathrm{ng} / \mathrm{ml}$ in nonsmoker group and the difference between the two groups was statistically significant $(P$ value $=0.00)$. hypertension was present in $26(43.3 \%)$ patients and the mean of plasma $25(\mathrm{OH}) \mathrm{D}$ levels was $10.09 \pm 9.6 \mathrm{ng} / \mathrm{ml}$ in this group, while the mean of plasma 25(OH)D levels was $15.09 \pm 9.02 \mathrm{ng} / \mathrm{ml}$ in patients without hypertension and the difference between the two groups was statistically significant $(P$ value $=0.04)$. The difference between the mean plasma 25(OH)D levels in patients with DM versus patients without DM was not statistically significant (11.5 \pm 8.1 versus $12.9 \pm 10.6, P=0.57)$.(fig. $1 \mathrm{~A}, 1 \mathrm{~B}$ and $1 \mathrm{C}$ ).
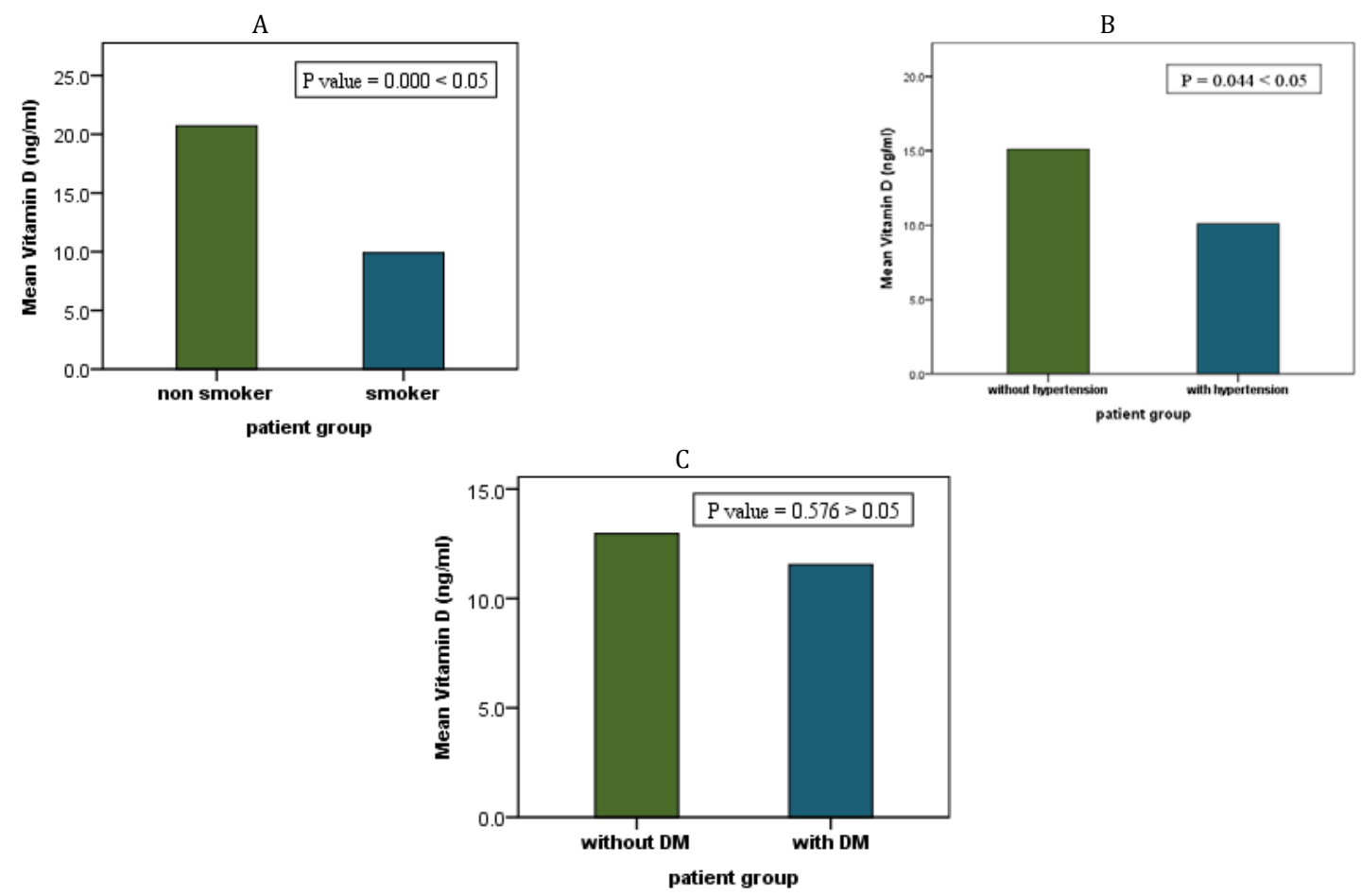

Fig. 1: The mean plasma 25(OH)D concentrations in acute coronary syndrome patients; A: between smokers and nonsmokers; B: those with and without hypertension; and C: those with and without diabetes mellitus (DM) 
After controlling for traditional cardiovascular risk factors, the association between 25(OH)D deficiency and acute coronary syndrome remained significant $(P$ value $=0.02)$. The patients were categorized into two groups according to their plasma 25(OH)D levels;
25(OH)D levels of $\geq 20 \mathrm{ng} / \mathrm{ml}$ were considered normal, while levels of $<20 \mathrm{ng} / \mathrm{ml}$ were classified as deficient. The baseline characteristics of cases in these groups are shown in table 2 . The only significant difference between the two groups of patients was in smoking status.

Table 2: Baseline characteristics of cases according to Vitamin D status

\begin{tabular}{|c|c|c|c|}
\hline \multirow[t]{2}{*}{ Variables } & \multicolumn{2}{|l|}{$25(0 H) D(n g / m l)$} & \multirow[b]{2}{*}{$P$ (value) } \\
\hline & $<20(\mathrm{~N}=47) 78.3 \%$ & $\geq 20(\mathrm{~N}=13) 21.7 \%$ & \\
\hline Age (years) & $56.8 \pm 10.5$ & $49.5 \pm 7.6$ & 0.06 \\
\hline Male/Female & $33(70.02 \%) / 14(29.8 \%)$ & $11(84.6 \%) / 2(15.4 \%)$ & 0.299 \\
\hline Hypertension & $28(59.6 \%)$ & $5(38.5 \%)$ & 0.176 \\
\hline Smoking & $37(78.7 \%)$ & $3(23.1 \%)$ & $0.000^{*}$ \\
\hline Diabetes Mellitus & $22(46.8 \%)$ & $4(30.8 \%)$ & 0.302 \\
\hline Previous Heart Disease & $22(46.8 \%)$ & $4(30.8 \%)$ & 0.302 \\
\hline
\end{tabular}

*Statistically significant difference between two groups $(P<0.05)$.

\section{DISCUSSION}

Although the best-characterized sequelae of vitamin D deficiency involve the musculoskeletal system, a growing body of evidence suggests that low levels of vitamin D may adversely affect the cardiovascular system [25]. In parallel, the recognition of the presence of widespread vitamin D deficiency is increasing $[8,16$, 26]. Recurrent predictors of hypovitaminosis $D$ throughout the Middle East are older age, female sex, multiple births, conservative dress, lower-income group, and urban living [27]. The consequences of this growing epidemic of vitamin D deficiency are still not well understood. However, recent reports of the associations of vitamin D deficiency with multiple CV conditions have been of great interest, suggesting the need for prospective validation and extended observations.

In this study, vitamin D deficiency was more common in the smoker groups and the effect of smoking on vitamin D metabolism may be one probable reason. Mechanisms by which smoking affects vitamin D metabolism are still unclear. One possibility is that chemicals in tobacco smoke may have a direct effect on vitamin $\mathrm{D}$ metabolism and function, like an accumulation of cadmium in the kidney [28].

In accordance to our study, Vitamin D deficiency has been shown to be associated with significant increase in the prevalence of hypertension, and this was in agreement with previous studies [29]. In the study of Forman et al. [30], during $4 \mathrm{y}$ of follow-up, men and women who had plasma $25(\mathrm{OH}) \mathrm{D}$ levels $<15 \mathrm{ng} / \mathrm{ml}$ were 3 times as likely to have a new diagnosis of hypertension in the next $4 \mathrm{y}$ compared with those with 25(OH)D levels $>30 \mathrm{ng} / \mathrm{ml}$. Of the potentially relevant mechanisms, vitamin $D$ deficiency activates the renin-angiotensin-aldosterone (RAAS) system, and excessive RAAS stimulation is associated with hypertension. Animal studies [7] show that vitamin $\mathrm{D}$ is an important regulator of the RAAS system and that 1,25-dihydroxyvitamin $\mathrm{D}$, the activated form of vitamin $\mathrm{D}$, suppresses renin gene expression. Disruption of the vitamin D receptor gene leads to elevated renin production, cardiac hypertrophy, and elevated blood pressure in mice [31].

In this study, we found no significant association between mean plasma vitamin D levels of ACS patients with diabetes mellitus in comparison with ACS patients without diabetes mellitus. Results relating vitamin D deficiency with glucose metabolism have been inconsistent. Chiu et al. [11] and Grimnes et al. [32] have found that hypovitaminosis D was associated with both decreased insulin secretion and insulin sensitivity, while de las Heras et al. [33] reported no such relationship. As recently reviewed by Alvarez et al. [34], many epidemiological studies have been reported that a low plasma vitamin D concentration may be associated with insulin resistance. However, in these studies, comparison groups were usually not well-matched for potential confounding factors such as age, race, BMI, obesity and physical activity. It should also be kept in mind that vitamin D deficiency in diabetic patients may partly be a consequence of reduced physical activity and consecutive obesity, as well as limited sun exposure. Therefore, residual confounding in observational studies due to the close link of obesity with both vitamin D deficiency and glucose intolerance cannot be ruled out with certainty $[35,36]$.

Our data suggest that vitamin D deficiency is associated with increased acute coronary syndrome risk, above and beyond established cardiovascular risk factors. We controlled for the traditional cardiovascular risk factors, including age, gender, smoking, hypertension, diabetes mellitus, and previous cardiovascular diseases. The results showed that the association between 25(OH)D deficiency and acute coronary syndrome remained significant $(P=0.02)$. Also, we studied the strength of this relation at cut-point for vitamin $D$ levels $(<20 \mathrm{ng} / \mathrm{ml})$ that compatible with at least moderate vitamin D deficiency. With this cut-point, the prevalence of vitamin D deficiency in the present cohort $(78.3 \%)$ was a considerable high but consistent with that reported in other epidemiological studies [24]. In the study of Lee $e t$ al. [37], the prevalence of vitamin D deficiency in the patients with plasma $25(\mathrm{OH}) \mathrm{D}$ levels $<20 \mathrm{ng} / \mathrm{ml}$ was up to $(74.9 \%)$. In addition, with this cut-point we did not find significant differences between the plasma vitamin D levels and traditional cardiovascular risk factors, except for smoking there was a significant correlation $(P=$ 0.00 ) due to the fact that smoking is considered a risk factor for vitamin D deficiency. The results of the current study are in accordance with the previous studies in the other countries. A prospective case-control study in the USA, of more than 18.000 men [14] found a statistically significant correlation between low 25(OH)D levels and an increased risk for myocardial infarction, even after adjustment for traditional cardiovascular risk factors. Severe vitamin $\mathrm{D}$ deficiency has been shown to be independently associated with in-hospital cardiovascular mortality in patients with acute coronary syndromes [38].

Clinical studies support a role for vitamin D in maintaining cardiovascular health through both the direct action of the vitamin D on cardiomyocytes and the indirect actions on circulating hormone and calcium levels [39]. Since the vitamin D receptor (VDR) is also expressed in the cardiomyocytes and vasculature, it is tempting to hypothesize that vitamin D may protect against atherosclerosis, vascular calcification and endothelial dysfunction [40]. It inhibits cardiomyocytes and smooth muscle cells proliferation [41]. In addition, Vitamin D has some anti-hypertrophic effects, suppression effect on the renin-angiotensin system, the modulatory effect on contractility and regulatory effect on extracellular matrix turnover [42].

The present study has some limitations, on top of the small size of our sample, and the fact that the study was conducted at one centre, we couldn't control for multiple confounders like sun exposure, and social status.

\section{CONCLUSION}

Our findings, taken in the context of previous observations, and the independent nature of this association between low 25(OH)D levels and acute coronary syndrome suggests that the relationship is not mediated by other risk factors, which indicates that vitamin D deficiency may 
represent an important new CV risk factor. Because vitamin D deficiency can be readily determined by blood testing and treated by supplementation, clinical trials are urgently needed to determine whether this represents a causal association and whether vitamin D replacement therapy can reduce the associated increase in CV risk.

\section{ACKNOWLEDGEMENT}

This work was supported by Aleppo University.

\section{AUTHORS CONTRIBUTIONS}

The experimental work was done by Dr. Aya Hallak under the supervision of Prof. Mohammad Yaser Abajy and Prof. Mahmoud Malhis. All authors read and approved the final manuscript.

\section{CONFLICT OF INTERESTS}

The authors have no conflicts of interest to disclose

\section{REFERENCES}

1. Adams JS, Hewison M. Update in vitamin D. J Clin Endocrinol Metab 2010;95:471-8.

2. Holick MF. High prevalence of vitamin D inadequacy and implications for health. Mayo Clin Proc 2006;81:353-73.

3. Malabanan A, Veronikis IE, Holick MF. Redefining vitamin D insufficiency. Lancet 1998;351:805-6.

4. Chapuy MC, Preziosi P, Maamer M, Arnaud S, Galan P, Hercberg $S$, et al. Prevalence of vitamin D insufficiency in an adult normal population. Osteoporos Int 1997;7:439-43.

5. Nesby-O’Dell S, Scanlon KS, Cogswell ME, Gillespie C, Hollis BW, Looker AC, et al. Hypovitaminosis $\mathrm{D}$ prevalence and determinants among African American and white women of reproductive age: third National Health and Nutrition Examination Survey, 1988-1994. Am J Clin Nutr 2002;76:187-92.

6. Barakat $\mathrm{K}$, Hitman GA. The emerging role of vitamin $\mathrm{D}$ and its receptor in the pathogenesis of acute coronary syndromes. $\mathrm{Br} \mathrm{J}$ Cardiol 2006;13:9-12.

7. Li YC, Qiao G, Uskokovic M, Xiang W, Zheng W, Kong J. Vitamin $D$ : a negative endocrine regulator of the renin-angiotensin system and blood pressure. J Steroid Biochem Mol Biol 2004;89-90:387-92.

8. Lee JH, O'Keefe JH, Bell D, Hensrud DD, Holick MF. Vitamin D deficiency an important, common, and easily treatable cardiovascular risk factor? J Am Coll Cardiol 2008;52:1949-56.

9. Ohsawa M, Koyama T, Yamamoto K. 1,25 dihydroxy vitamin D3 and its synthetic analogs downregulate tissue factor and upregulate thrombomodulin expression in monocytic cells, counteracting the effects of TNF, and oxidised LDL. Circulation 2000;102:2867-72.

10. Muller K, Haahr PM, Diamant M, Rieneck K, Kharazmi A, Bendtzen K. 1,25-Dihydroxyvitamin D3 inhibits cytokine production by human blood monocytes at the posttranscriptional level. Cytokine 1992;4:506-12.

11. Chiu KC, Chu A, Go VL, Saad MF. Hypovitaminosis D is associated with insulin resistance and beta cell dysfunction. Am J Clin Nutr 2004;79:820-5.

12. Durgarao Y, Poornima AM, Prabha A, ARUN S, Chakrapani M, Rukmini MS. Predominance and influence of vitamin D deficiency on glycemic and lipid indices in type 2 diabetes patients: a case-control study. Asian J Pharm Clin Res 2017; 10:177-80.

13. Wang TJ, Pencina MJ, Booth SL, Jacques PF, Ingelsson E, Lanier $\mathrm{K}$, et al. Vitamin D deficiency and risk of cardiovascular disease. Circulation 2008;117:503-11.

14. Giovannucci E, Liu Y, Hollis BW, Rimm EB. 25-Hydroxyvitamin $\mathrm{D}$ and risk of myocardial infarction in men: a prospective study. Arch Intern Med 2008;168:1174-80.

15. Hallak A, Malhis M, Abajy MY. Prevalence of vitamin-D deficiency in patients with acute coronary syndrome in syria. Int J Pharm Sci Nanotech 2016;9:3544-8.

16. Holick MF. Vitamin D deficiency. N Engl J Med 2007;357:266-81.

17. Wallis DE, Penckofer S, Sizemore GW. The "sunshine deficit" and cardiovascular disease. Circulation 2008;118:1476-85.
18. Wolf M, Shah A, Gutierrez O, Ankers E, Monroy M, Tamez H, et al. Vitamin D levels and early mortality among incident hemodialysis patients. Kidney Int 2007;72:1004-13.

19. Dobnig H, Pilz S, Scharnagl H, Renner W, Seelhorst U, Wellnitz $\mathrm{B}$, et al. Independent association of low serum 25hydroxyvitamin D and 1,25-dihydroxy vitamin D levels with allcause and cardiovascular mortality. Arch Intern Med 2008;168:1340-9.

20. Pittas AG, Chung M, Trikalinos T, Mitri J, Brendel M, Patel K, et al. Systematic review: vitamin $\mathrm{D}$ and cardiometabolic outcomes. Ann Intern Med 2010;152:307-14.

21. Alpert JS, Thygesen K, Antman E. Myocardial infarction redefined: a consensus document of The Joint European Society of Cardiology/American College of Cardiology Committee for the Redefinition of Myocardial Infarction. J Am Coll Cardiol 2000;36:959-69.

22. Chobanian AV, Bakris GL, Black HR, Cushman WC, Green LA, Izzo JL, et al. Seventh report of the joint national committee on prevention, detection, evaluation, and treatment of high blood pressure. Hypertension 2003;42:1206-52.

23. Report of the Expert Committee on the Diagnosis and Classification of Diabetes Mellitus. Diabetes Care 1997;20: 1183-97.

24. Bischoff-Ferrari HA, Giovannucci E, Willett WC, Dietrich T, Dawson-Hughes B. Estimation of optimal serum concentrations of 25-hydroxyvitamin D for multiple health outcomes. Am J Clin Nutr 2006;84:18-28.

25. Zittermann A, Schleithoff SS, Koerfer R. Putting cardiovascular disease and vitamin D insufficiency into perspective. Br J Nutr 2005;94:483-92.

26. Harsh A, Vivek D, Nidhi S. Evaluation of knowledge, practices of vitamin $\mathrm{D}$ and attitude toward sunlight among Indian students. Asian J Pharm Clin Res 2016;9:308-13.

27. Mithal A, Wahl DA, Bonjour JP, Burckhardt P, Dawson-Hughes B, Eisman JA, et al. IOF committee of scientific advisors (CSA) nutrition working group: global vitamin D status and determinants of hypovitaminosis D. Osteoporos Int 2009; 20:1807-20.

28. Brot C, Jorgensen NR, Sorensen $\mathrm{OH}$. The influence of smoking on vitamin D status and calcium metabolism. Eur J Clin Nutr 1999;53:920-6.

29. Witham MD, Nadir MA, Struthers AD. Effect of vitamin D on blood pressure: a systematic review and meta-analysis. J Hypertens 2009;27:1948-54.

30. Forman JP, Giovannucci E, Holmes MD, Bischoff-Ferrari HA, Tworoger SS, Willett WC, et al. Plasma 25-hydroxyvitamin D levels and risk of incident hypertension. Hypertension 2007;49:1063-9.

31. Xiang W, Kong J, Chen S, Cao LP, Qiao G, Zheng W, et al. Cardiac hypertrophy in vitamin $D$ receptor knockout mice: role of the systemic and cardiac renin-angiotensin systems. Am J Physiol Endocrinol Metab 2005;288:125-32.

32. Grimnes G, Figenschau Y, Almas B, Jorde R. Vitamin D insulin secretion,sensitivity, and lipids: results from a case-control study and a randomized controlled trial using hyperglycemic clamp technique. Diabetes 2011;60:2748-57.

33. De las Heras J, Rajakumar K, Lee S, Bacha F, Holick MF, Arslanian SA. 25-Hydroxyvitamin D in obese youth across the spectrum of glucose tolerance from normal to prediabetes to type 2 diabetes. Diabetes Care 2013;36:2048-53.

34. Alvarez JA, Ashraf A. Role of vitamin D in insulin secretion and insulin sensitivity for glucose homeostasis. Int J Endocrinol 2010:351-85. Doi:10.1155/2010/351385.

35. Wortsman J, Matsuoka LY, Chen TC, Lu Z, Holick MF. Decreased bioavailability of vitamin D in obesity. Am J Clin Nutr 2000;72:690-3

36. Kabadi SM, Lee BK, Liu L. Joint effects of obesity and vitamin D insufficiency on insulin resistance and type 2 diabetes: results from the NHANES 2001-2006. Diabetes Care 2012;35:2048-54.

37. Lee JH, Gadi R, Spertus JA, Tang F, O'Keefe JH. Prevalence of vitamin $\mathrm{D}$ deficiency in patients with acute myocardial infarction. Am J Cardiol 2011;107:1636-8.

38. Correia LC, Sodre F, Garcia G, Sabino M, Brito M, Kalil F, et al. Relation of severe deficiency of vitamin $\mathrm{D}$ to cardiovascular 
mortality during acute coronary syndromes. Am J Cardiol 2013;111:324-7.

39. Aggarwal N, Reis JP, Michos ED. Vitamin D deficiency and its implications on cardiovascular disease. Curr Cardio Risk Rep 2010;4:68-75.

40. Brewer LC, Michos ED, Reis JP. Vitamin D in atherosclerosis, vascular disease, and endothelial function. Curr Drug Targets 2011;12:54-60.
41. Kim DH, Sabour S, Sagar, Adams S, Whellan DJ. Prevalence of hypovitaminosis D in cardiovascular diseases (from the National Health and Nutrition Examination Survey 2001 to 2004). Am J Cardiol 2008;102:1540-4.

42. Pilz S, Tomaschitz A, Marz W, Drechsler C, Ritz E, Zittermann A, et al. Vitamin D, cardiovascular disease and mortality. Clin Endocrinol (Oxf) 2011;75:575-84. 